\title{
Learning to apply the pocket ultrasound device on the critically ill: comparing six 'quick-look' signs for quality and prognostic values during initial use by novices
}

\author{
Tuan V Mai, David J Shaw, Stanley A Amundson, Donna L Agan and Bruce J Kimura*
}

See related research by Biais et al., http://ccforum.com/content/16/3/R82

Biais and colleagues [1] have shown that echocardiographers can adequately perform a three-view cardiac examination in the emergency setting using a pocket ultrasound device (PUD). We have similarly noted that an evidencebased 'quick-look', cardiac limited ultrasound examination has diagnostic and prognostic value [2], can affect medical decision-making [3], and can be successfully taught to internal medicine residents [4]. As few data describe the learning curve of ultrasound imaging with PUDs, we observed the initial quality and prognostic value of six 'quicklook' signs obtained by residents learning to use the PUD.

Internal medicine residents in an ultrasound training program [4] recorded a brief, previously described [2] cardiac limited ultrasound examination designed to detect six 'quick-look' signs of left ventricular systolic dysfunction, left atrial enlargement, ultrasound lung comet (ULC) tail artifact representing interstitial lung edema, elevated central venous pressure, pleural effusion, and right ventricular enlargement on a convenience-sample of intensive care unit (ICU) patients with respiratory failure, shock, or severe cardiac disease, using a PUD (Vscan, GE Healthcare, Wauwatosa, WI, USA). An expert echocardiographer reviewed the resident-acquired images and assigned a quality score: 0 (no image), 1 (only motion detected; off-axis), 2 ('suboptimal', poor delineation of structures), 3 ('adequate' for diagnosis of particular sign), or 4 ('optimal', good delineation of all structures).
Only technically adequate quality views (score $>2$ ) were entered into a multivariate logistic regression combining the six signs, clinical presentation and inpatient mortality (SPSS version 12.0). A $P$-value $<0.05$ was considered statistically significant. The Scripps Institutional Review Board approved the study.

Twenty-one residents recorded 749 views on 107 critically ill patients (mean 5.1 patients/resident): mean patient age of $65.2 \pm 16.8$ years, inpatient mortality of $25.2 \%$, and mean quality score of $2.1 \pm 1.4$. Presentation, mortality and overall percentage adequate quality views were: respiratory failure $(n=55,32.7 \%, 48.0 \%)$, shock $(\mathrm{n}=16,25.0 \%, 51.6 \%)$ and cardiac disease $(\mathrm{n}=36,13.9 \%$, $51.7 \%)$. ULC had the most adequate quality images and is the only sign that had statistically significant prognostic value in the residents' and cardiologist's interpretations (Table 1).

Galen cautioned against extrapolating Biais and colleagues' data for non-expert users [5]. As few studies address the learning curve of quick-look ultrasound imaging tasks, this study suggests that novice users learning to use the PUD readily learn to image ULC, which was prognostic in this ICU population. In light of a substantial number of initially difficult parasternal long-axis and subcostal views, the PUD's most simple and immediate use may be in the rapid detection of life-threatening pulmonary edema.

\section{Authors' response}

Cédric Carrié and Matthieu Biais

\footnotetext{
* Correspondence: kimura.bruce@scrippshealth.org

Department of Medical Education, Scripps Mercy Hospital, 4077 Fifth Avenue, MER-35, San Diego, CA 92103, USA
}

Recently developed, the new generation of PUDs made real the concept of an ultrasonic stethoscope. But at least three questions remained: first, what is the true diagnostic capacities of these PUDs; second, in which clinical settings should 


\begin{tabular}{|c|c|c|c|c|c|}
\hline Sign & $\begin{array}{l}\text { Technically } \\
\text { adequate } \\
\text { quality }\end{array}$ & $\begin{array}{l}\text { Mortality } \\
\text { odds ratios } \\
\text { (resident } \\
\text { inter- } \\
\text { pretation) }\end{array}$ & $95 \% \mathrm{Cl}$ & $\begin{array}{c}\text { Mortality } \\
\text { odds ratios } \\
\text { (cardiologist } \\
\text { inter- } \\
\text { pretation) }\end{array}$ & $95 \% \mathrm{Cl}$ \\
\hline LVD & $42.1 \%$ & 0.6 & {$[0.1,2.2]$} & 0.4 & {$[0.1,2.2]$} \\
\hline LAE & $43.9 \%$ & 3.8 & {$[0.7,19.7]$} & 1.7 & {$[0.4,6.6]$} \\
\hline ULC & $81.3 \%$ & 3.0 & {$[1.1,7.9]$} & 3.0 & {$[1.1,7.9]$} \\
\hline Pleu. eff. & $59.8 \%$ & 6.067 & {$[1.5,24.1]$} & 2.4 & {$[0.7,7.9]$} \\
\hline RVE & $49.5 \%$ & 0.4 & {$[0.8,2.2]$} & 0.6 & {$[0.1,3.1]$} \\
\hline eCVP & $36.0 \%$ & 3.8 & $[0.6,22.0]]$ & 1.1 & {$[0.2,5.8]$} \\
\hline
\end{tabular}

$\mathrm{Cl}$, confidence interval; eCVP, elevated central venous pressure; $L A E$, left atrial enlargement; LVD, left ventricular systolic dysfunction; Pleu. eff., pleural effusion; RVE, right ventricular enlargement; ULC, ultrasound lung comet tail artifact. The numbers in bold represent mortality odd ratios that are statistically significant $(P<0.05)$

they be used; and third, what is the level of competence needed for its optimal use?

After several years of experience with PUDs, we have demonstrated its reliability for goal-directed examinations aiming to answer brief and important clinical questions encountered by front-line physicians in the emergency setting $[1,6]$. However, those examinations were performed by operators sensitized to a visual assessment of semiquantitative parameters. Therefore, our results could not be extrapolated for non-expert users.

Here, Mai and colleagues report their experience in implementing a training curriculum dedicated to residents learning to use a PUD. Their observations are in accordance with the literature. Previously published studies evaluated the feasibility and the efficiency of limited training programs to reach recommended competencies in basic echocardiography and general ultrasound. Most of these studies were performed in emergency or critical care settings $[7,8]$. However, the duration of theoretical and practical sessions varied considerably across studies, explaining the lack of uniformity and generally accepted standards in basic ultrasound education among emergency medicine residents.

Thus, we insist on the need to define the specific learning curve of emergency residents for the acquisition of technical and cognitive skills in goal-directed emergency ultrasound. We continue to support the concept of a three-level system for training in ultrasound, as a limited field of competence cannot substitute for a more comprehensive imaging examination when indicated [9].
Competing interests

The authors declare that they have no competing interests.

\section{Authors' contributions}

TVM, DJS, SAA, DLA and BJK had full access to all of the data in the study and take responsibility for the integrity of the data and the accuracy of the data analysis. Study concept and design: TVM, DJS, SAA, and BJK. Acquisition of data: TVM and BJK. Analysis and interpretation of data: TVM and BJK. Drafting of the manuscript: TVM and BJK. Statistical analysis: TVM, DLA and BJK. Administrative, technical, and material support: DJS, SAA, and BJK. Study supervision: BJK. DJS and the graduate medical education office of Scripps Mercy Hospital provided the Vscan (GE Healthcare) ultrasonic stethoscope. All authors read and approved the final manuscript.

\section{Acknowledgements}

We thank all the 21 residents who participated in this study by using the pocket ultrasound device to assess for the six 'quick-look' signs during their initial evaluation of critically ill patients. The opinions, results, and conclusions reported in this research letter are those of the authors and are independent of any funding sources.

Published: 04 Sep 2013

\section{References}

1. Biais M, Carrié C, Delaunay F, Morel N, Revel P, Janvier G: Evaluation of a new pocket echoscopic device for focused cardiac ultrasonography in an emergency setting. Crit Care 2012, 16:R82.

2. Kimura BJ, Yogo N, O'Connell CW, Phan JN, Showalter BK, Wolfson T: Cardiopulmonary limited ultrasound examination for ' quick-look' bedside application. Am J Cardiol 2011, 108:586-590.

3. Kimura BJ, Shaw DJ, Agan DL, Amundson SA, Ping AC, DeMaria AN: Value of a cardiovascular limited ultrasound examination using a hand-carried device on clinical management in an outpatient medical clinic. Am J Cardiol 2007, 100:321-325.

4. Kimura BJ, Amundson SA, Phan JN, Agan DL, Shaw DJ: Observations during development of an internal medicine residency training program in cardiovascular limited ultrasound examination. J Hosp Med 2012, 7:537-542.

5. Galen HT: Is pocket ultrasound ready for prime time? Crit Care 2012, 16:463.

6. Carrié C, Delaunay F, Morel N, Revel P, Janvier G, Biais M: Ability of a new pocket echoscopic device to detect abdominal and pleural effusion in blunt trauma patients. Am J Emerg Med 2013, 31:437-439.

7. Vignon P, Mucke F, Bellec F, Marin B, Croce J, Brouqui T, Palobart C, Senges P, Truffy C, Wachmann A, Dugard A, Amiel JB: Basic critical care echocardiography: validation of a curriculum dedicated to noncardiologist residents. Crit Care Med 2011, 39:636-642.

8. Jones AE, Tayal VS, Kline JA: Focused training of emergency medicine residents in goal-directed echocardiography: a prospective study. Acad Emerg Med 2003, 10:1054-1058.

9. Mayo PH, Beaulieu Y, Doelken P, Feller-Kopman D, Harrod C, Kaplan A, Oropello J, Vieillard-Baron A, Slama M, Cholley B, Janvier G, Vignon P: Echocardiography in the intensive care unit: from evolution to revolution? Intensive Care Med 2008, 34:243-249.

\section{$10.1186 / \mathrm{cc} 12875$}

Cite this article as: Mai et al:: Learning to apply the pocket ultrasound device on the critically ill: comparing six 'quick-look' signs for quality and prognostic values during initial use by novices. Critical Care $2013,17: 448$

\section{Abbreviations}

ICU: Intensive care unit; PUD: Pocket ultrasound device; ULC: Ultrasound lung comet. 